\title{
Seroprevalence of $Q$ Fever and Brucellosis in Domestic and Imported Cattle of Southeastern Iran
}

\author{
Ahmad Ghasemi ${ }^{1,2,3}$, Mohammad Reza Hajinezhad ${ }^{4}$, Saber Esmaeili1,2,3, Ehsan Mostafavi1,2* \\ ${ }^{1}$ National Reference Laboratory for Plague, Tularemia and Q Fever, Research Centre for Emerging and Reemerging \\ Infectious Diseases, Pasteur Institute of Iran, Akanlu, Kabudar-Ahang, Hamadan, Iran; 2Department of \\ Epidemiology and Biostatistics, Research Centre for Emerging and Reemerging Infectious Diseases, Pasteur Institute \\ of Iran, Tehran, Iran; ${ }^{3}$ Department of Bacteriology, Faculty of Medical science, Tarbiat Modares University, Tehran, \\ Iran; ${ }^{4}$ Department of Basic Science, Veterinary Medicine Faculty, University of Zabol, Zabol, Iran
}

\section{Received Aug 11, 2018; Accepted Sep 29, 2018}

\begin{abstract}
Introduction: Q fever and brucellosis caused by Coxiella burnetii and Brucella spp., respectively are among the significant zoonotic infectious diseases worldwide affecting both humans and domestic animals. Iran and its neighboring countries in the east are endemic for these diseases. This study, conducted in 2011-2012, aimed to determine the seroprevalence of Q fever and brucellosis among domestic and imported cattle slaughtered in Zabol city of Sistan and Baluchistan province, eastern Iran. Methods: We collected blood samples from 103 imported and 62 domestic animals. The Sera were separated and examined by an ELISA test for the presence of IgG against the two causative agents. Results: The seroprevalence of brucellosis in imported cattle was $0.97 \%$, while none of the domestic animals turned positive. Seroprevalence of Q fever in domestic cattle was $3.23 \%$, whereas all imported cattle were negative. Conclusion: In this study, brucellosis and Q fever exhibited a very low seroprevalence in domestic and imported animals. Further studies on other livestock would provide more information on the status of these diseases in the southeast of Iran. Furthermore, studies on the prevalence of these diseases in border regions and neighboring countries of Sistan and Baluchistan would provide more in-depth insights into these diseases and the possibility of their importation to Iran. J Med Microbiol Infec Dis, 2018, 6 (2-3): 48-52.
\end{abstract}

Keywords: Q Fever, Zoonoses, Coxiella burnetii, Brucella, Iran.

\section{INTRODUCTION}

About 60 to $75 \%$ of infectious diseases in humans are zoonotic. These diseases are of great concern worldwide due to their increasing public health threat and their negative impact on livestock production, trade, travel and economy [1-3].

Q fever is one of the controversial zoonotic diseases with a global distribution. The causative agent, Coxiella burnetii, occurs in a wide range of domestic and wild animals $[4,5]$. This bacteria is relatively resistant to environmental conditions and can spread by wind [6]. In nature, livestock (cattle, goats, sheep, and camels) are the primary reservoir of this bacteria [7]. This pathogen occurs with high concentrations in the placenta, amniotic fluid and birth products of infected animals [8]. Infection with this agent in animals can lead to abortion and stillbirth, infertility, the birth of weak calves and pneumonia [8, 9]. The primary route of human infection by this organism is via aerosols, i.e., inhalation of aerosols. Also, the disease transmission can occur by consumption of the contaminated foods including dairy products, eggs, and other livestock products, and rarely by tick bites [6]. This disease is regarded as an occupational disease of the ranchers, farmers, veterinarians and slaughterhouse workers [8].

The bacterium, C. burnetii, is a highly infectious pathogen of humans and infection with it appears in two forms of the disease, acute and chronic. Acute Q fever is a self-limiting disease with manifestations of fever, chills, headache, muscle aches and weakness. It is mostly characterized by pneumonia, hepatitis, prolonged fever and meningoencephalitis [8]. Chronic Q fever is mainly associated with endocarditis causing 6 to $65 \%$ mortality [6, 8]. Both forms of acute and chronic, are recognized by detection of IgGs developed against the bacterial antigens in phase I and II of the disease $[4,10]$.

Q fever is endemic to Iran, and there are reports of both forms of the disease, chronic and acute Q fever, among humans [11]. Moreover, there are many reports on livestock infections from different parts of the country [11-18].

Brucella spp. are gram-negative intracellular bacteria [19]. The incidence of brucellosis has significantly declined

${ }^{*}$ Correspondence: Ehsan Mostafavi

Department of Epidemiology and Biostatistics, Research Centre for Emerging and Reemerging Infectious Diseases, Pasteur Institute of Iran, No. 69, Pasteur Ave, Tehran, Iran, 1316943551.

Email: mostafavi@pasteur.ac.ir

Tel/Fax: +98 (21) 64112121 
in industrialized countries, but in most developing countries the disease remains a significant public health concern [20, 21]. The human infections exhibit various symptoms whereas in livestock the infection mainly results in abortion in late pregnancy, infertility, testicular swelling and impaired fertility [10, 22]. Brucella abortus is the primary cause of abortion in cattle, and the material from ruminants' miscarriages are the primary source of bacteria for humans and animals infection [7, 23].

Annually, more than 500 thousand human infections of brucellosis are reported worldwide, mostly from developing countries [24]. This infection can be transmitted through consumption of contaminated foods, direct contact with broken skin and mucosal membranes (including conjunctivitis), and inhalation of aerosols (in slaughterhouse and laboratories) [19, 21]. In humans, the disease causes a wide range of symptoms including the typical undulant fever. The most common manifestation in humans is a flu-like illness appearing as atypical pneumonia [7, 23]. This bacterial infection causes a very severe debilitating disease, with clinical presentations like fever, sweats, weakness, weight loss, headache, and continuous joint pain lasting few weeks to years. Neurological complications, endocarditis, and testis infection or bone abscesses can also occur [22]. The disease has substantial economic impacts on animal productivity in the affected countries [15, 25, 26]. In Iran, brucellosis is a significant infectious disease affecting more than 20 thousand people annually, which reflect the high burden of the disease in the country [27].

Brucellosis is endemic to the neighboring countries, e.g., Afghanistan and Pakistan in the east of Iran [28]. In Afghanistan, brucellosis was reported among $1.3 \%$ of livestock (1.4\% in sheep, $1.5 \%$ in goats, $0.3 \%$ in cattle) by ELISA methods and Q fever exhibited a prevalence of $41.3 \%$ among these animals (43.4\% in sheep, $52.7 \%$ in goats, and $5.2 \%$ in cattle) [29]. In Pakistan, $Q$ fever infection was detected in $17.9 \%$ of the sheep and $16.4 \%$ of goats by ELISA methods, and brucellosis was reported in $6 \%$ of livestock [30, 31].

Many livestock from Afghanistan and Pakistan are imported to Iran via the borders of Sistan and Baluchistan province, and Zabol city in the north of this province is one of the main transit points for the importation of the livestock. Regarding the possibility of the introduction of $\mathrm{Q}$ fever and brucellosis-infected livestock to Iran through Zabol city, we prompted to investigate the seroprevalence of these diseases in domestic and imported cattle in this region.

\section{MATERIAL AND METHODS}

Sample collection. Samples were collected during 2011-2012 from the industrial slaughterhouse of Zabol city. Blood samples were obtained from the jugular vein using Venoject tubes before slaughtering of the animals. A questionnaire was filled containing the information about age, gender, history of abortion and illness of the animals. Blood samples were transferred to the laboratory at the ambient temperature and were centrifuged at $3000 \mathrm{rpm}$ for
10 min to separate the sera. The sera were kept at $-20^{\circ} \mathrm{C}$ until they were transferred to Pasteur Institute of Iran.

Detection of anti-C. burnetii IgGs. Sera were tested to detect IgG antibodies against $C$. burnetii using a commercial ELISA kit (US, IDEXX) according to the manufacturer's recommendations. The optical density at 450 nm (OD450) was measured by an ELISA reader. A cutoff was defined as specified by the kit manufacturer and the positive, negative and suspicious samples were identified accordingly.

Detection of anti-Brucella IgGs. A commercial ELISA kit (US IDEXX) was used to detect Brucella spp antibodies. The ELISA was performed according to the manufacturer's instructions. The optical density of the samples at $450 \mathrm{~nm}$ (OD450) was measured by an ELISA reader. Based on a cut-off specified by the kit manufacturer, the positive, negative and suspicious samples were identified.

Statistical analysis of data. Stata software version 11 was used for data analysis. For comparison of the results, chi-square and Fisher's exact test were used and $P$-values less than 0.05 were considered statistically significant.

\section{RESULTS}

In this study, sera of 165 cattle (103 imported and 62 domestic) were tested; $80.6 \%$ belonged to male animals, and $43 \%$ were over two years old.

Out of 165 livestock, only one imported cattle (0.97\%) had anti-Brucella IgGs, and the rest of the animals were negative. Our results also showed that in domestic animals, two cases (3.23\%) were positive and four (6.45\%) had antibodies at borderline for $\mathrm{Q}$ fever. No positive $\mathrm{Q}$ fever livestock was observed among the imported animals, but four cases (3.88\%) had IgG antibodies at borderline.

There were no significant correlations between the type of cattle (domestic and imported) and the infection rate. Also, between gender and age and the prevalence of diseases, no significant correlation was observed (Table 1). While $3.23 \%$ of the domestic cattle and none of the imported animals were seropositive for brucellosis, and also no domestic cattle and $0.97 \%$ of imported cattle were seropositive for $\mathrm{Q}$ fever, these difference were not statistically significant.

\section{DISCUSSION}

This study aimed to investigate the seroprevalence of two major zoonotic bacterial diseases, brucellosis and $\mathrm{Q}$ fever among the slaughtered cattle in Zabol city. The seroprevalence of $\mathrm{Q}$ fever and brucellosis was $1.27 \%$ and $0.61 \%$, respectively. There was no significant relationship between age, gender, and the animal species with the prevalence of the two infections.

This finding was consistent with other similar studies in Iran and the world [32, 33]. In some studies, age showed to be as risk factor for contraction of infectious diseases [22, 34].

Several studies conducted in different countries showed that gender was not a risk factor for $\mathrm{Q}$ fever, which is in 
Table 1. Prevalence of brucellosis and Q fever based on livestock species, age, and sex

\begin{tabular}{|c|c|c|c|c|c|c|}
\hline \multirow{2}{*}{\multicolumn{2}{|c|}{ Variable }} & \multirow{3}{*}{$\begin{array}{c}\text { No. } \\
62 \\
103\end{array}$} & \multicolumn{2}{|c|}{ Brucellosis } & \multicolumn{2}{|l|}{ Q fever } \\
\hline & & & No. of positive sera (\%) & $P$-value & No. of positive sera (\%) & $P$-value \\
\hline Type of studied cattle & Domestic & & $\begin{array}{l}2(3.23) \\
0(0.00)\end{array}$ & 0.14 & $0(0.00)$ & 1 \\
\hline Gender & $\begin{array}{c}\text { Male } \\
\text { Female }\end{array}$ & $\begin{array}{c}133 \\
32\end{array}$ & $\begin{array}{l}1(0.75) \\
1(3.13)\end{array}$ & 0.35 & $\begin{array}{l}1(0.75) \\
0(0.00)\end{array}$ & 1 \\
\hline Age (year) & $\begin{array}{l}2> \\
2 \leq\end{array}$ & $\begin{array}{l}71 \\
94\end{array}$ & $\begin{array}{l}1(1.41) \\
1(1.06)\end{array}$ & 1 & $\begin{array}{l}1(1.41) \\
0(0.00)\end{array}$ & 0.43 \\
\hline Total & - & 165 & $2(0.61)$ & - & $1(1.21)$ & - \\
\hline
\end{tabular}

parallel to the results obtained in our study [22, 32]. Some other studies considered the gender as a risk factor that dairy cows aged three years had the highest seroprevalence [35].

In this study, no significant correlation was observed between age and seroprevalence of brucellosis, which was consistent with similar studies in Iran [36]. However, in some studies, age showed to be a risk factor and rate of infection increased with the age [37, 38].

In this study, there was no significant association ( $p=0.35$ ) between Brucella seropositivity and the animals' gender, while the rate of infection in the females was higher than males, which matched the results of a similar study in Zimbabwe [38], but in contrast to a study in Nigeria [39].

The seroprevalence rate of $\mathrm{Q}$ fever $(1.27 \%)$ and brucellosis $(0.61 \%)$ obtained in the present study was much lower than the similar studies in Iran and neighboring countries (Table 2). The low prevalence of $\mathrm{Q}$ fever and Brucellosis in both the imported and domestic cattle in this study was surprising and unexpected and demands further studies in this region to gain a better insight of the status of these diseases.

Table 2. The results of studies on the prevalence of Q fever and brucellosis among cattle in Iran and neighboring countries

\begin{tabular}{|c|c|c|c|c|c|c|}
\hline & \multirow{2}{*}{ Location } & \multirow{2}{*}{ Time } & \multirow{2}{*}{ Number of studied cattle } & \multicolumn{2}{|c|}{ Prevalence of infection (\%) } & \multirow{2}{*}{ Reference } \\
\hline & & & & Q fever & Brucellosis & \\
\hline \multirow{5}{*}{ Iran } & Mazandaran & 2008 & 102 & 0 & - & [40] \\
\hline & Kerman & 2009 & 93 & 10.75 & - & [41] \\
\hline & Hamadan & 2015 & 120 & 0.83 & - & {$[32]$} \\
\hline & Isfahan & 2011 & 247 & 3.2 & - & {$[42]$} \\
\hline & Turkey & 2000 & 416 & 5.8 & - & [43] \\
\hline \multirow{4}{*}{ Iran } & Afghanistan & 2015 & 334 & 5.2 & 0.3 & [29] \\
\hline & Sarab & 2011 & 600 & - & 3.66 & {$[44]$} \\
\hline & Urmia & 2010 & 256 & - & 1.77 & [45] \\
\hline & Shabestar & 2013 & 50 & - & 10 & {$[46]$} \\
\hline & Pakistan & 2013 & 1168 & - & 6.9 & [47] \\
\hline & Pakistan & 2013 & 275 & - & 4.7 & [48] \\
\hline & Afghanistan & 2013 & & 5.2 & 0.29 & [49] \\
\hline
\end{tabular}

One of the flaws of this study was the lack of access to the information on the slaughtered cattle such as the parturitions, history of abortion, and vaccination. This limitation was because the purchasers of the cows were not aware of the history of the animals.

Further studies on the other domestic and imported livestock such as sheep and goat in southeastern provinces would provide a better insight into the epidemiological status of these diseases in this area and the possibility of their importation to Iran from neighboring countries.

\section{ACKNOWLEDGEMENT}

We would like to thank the staff of Zabol veterinary network and the industrial slaughterhouse of Zabol who assisted us for the collection of blood samples. The Centre for Communicable Diseases and the Pasteur Institute of Iran funded the project (Grant no. 810).

\section{CONFLICT OF INTEREST}

The authors declare that there are no conflicts of interest associated with this manuscript.

\section{REFERENCES}

1. Vrbova L, Stephen C, Kasman N, Boehnke R, Doyle-Waters M, Chablitt-Clark A, et al. Systematic review of surveillance systems for emerging zoonoses. Transbound Emerg Dis. 2010; 57 (3): 154-61.

2. Cantas L, Suer K. Review: the important bacterial zoonoses in “one health” concept. Front Public Health. 2014; 2: 144.

3. Katare M, Kumar $M$. Emerging zoonoses and their determinants. Vet World. 2010; 3: 481-4.

4. Dijkstra F, Hoek W, Wijers N, Schimmer B, Rietveld A, Wijkmans CJ, Vellema P, Schneeberger PM. The 2007-2010 Q fever epidemic in the Netherlands: characteristics of notified acute Q fever patients and the association with dairy goat farming. FEMS Immunol Med Microbiol. 2012; 64 (1): 3-12. 
5. Angelakis E, Raoult D. Q fever. Vet Microbiol. 2010; 140 (3): 297-309.

6. Takahashi H, Tokue Y, Kikuchi T, Kobayashi T, Gomi K, Goto I, et al. Prevalence of community-acquired respiratory tract infections associated with Q fever in Japan. Diagn Microbiol Infect Dis. 2004; 48 (4): 247-52.

7. Nakoune E, Debaere O, Koumanda-Kotogne F, Selekon B, Samory F, Talarmin A. Serological surveillance of brucellosis and Q fever in cattle in the Central African Republic. Acta Trop. 2004; 92 (2): 147-51.

8. Maurin M, Raoult Df. Q fever. Clin Microbiol Rev. 1999; 12 (4): 518-53.

9. Arricau-Bouvery N, Rodolakis A. Is Q fever an emerging or re-emerging zoonosis. Vet Res. 2005; 36 (3): 327-49.

10. Frankel D, Richet H, Renvoisé A, Raoult D. Q fever in France, 1985-2009. Emerg Infect Dis. 2011; 17 (3): 350-6.

11. Yaghmaie F, Esmaeili S, Francis SA, Mostafavi E. Q fever endocarditis in Iran: A case report. J Infect Public Health. 2015; 8 (5): 498-501.

12. Mostafavi E, Rastad H, Khalili M. Q Fever: An emerging public health concern in Iran. Asian J Epidemiol. 2012; 5 (3): 66.

13. Kayedi MH, Mokhayeri H, Birjandi M, Chegeni-Sharafi A, Esmaeili S, Mostafavi E. Seroepidemiological study of Q fever in Lorestan province, western Iran, 2014. Iran J Microbiol. 2017; 9 (4): 213-8.

14. Esmaeili S, Golzar F, Ayubi E, Naghili B, Mostafavi E. Acute Q fever in febrile patients in northwestern of Iran. PLoS Negl Trop Dis. 2017; 11 (4): e0005535.

15. Esmaeili S, Naddaf SR, Pourhossein B, Shahraki AH, Amiri FB, Gouya MM, Mostafavi E. Seroprevalence of Brucellosis, Leptospirosis, and Q Fever among Butchers and Slaughterhouse Workers in South-Eastern Iran. PloS one. 2016; 11 (1).

16. Esmaeili S, Pourhossein B, Gouya MM, Amiri FB, Mostafavi E. Seroepidemiological survey of $Q$ fever and brucellosis in Kurdistan Province, western Iran. Vector Borne Zoonotic Dis. 2014; 14 (1): 41-5.

17. Esmaeili S, Mostafavi E, Shahdordizadeh M, Mahmoudi H. A seroepidemiological survey of $\mathrm{Q}$ fever among sheep in Mazandaran province, northern Iran. AAEM. 2013; 20 (4): 70810.

18. Mostafavi E, Esmaeili S, Shahdordizadeh M, Mahmoudi H, Liriayii H, Amiri FB. Seroepidemiological feature of $\mathrm{Q}$ fever among sheep in Northern Iran. Retrovirology. 2012; 9 (Suppl 1): P40.

19. Al Dahouk S, Nöckler K, Hensel A, Tomaso H, Scholz H, Hagen R, et al. Human brucellosis in a nonendemic country: a report from Germany, 2002 and 2003. Eur J Clin Microbiol Infect Dis. 2005; 24 (7): 450-6.

20. Salari M. Seroepidemiological survey of Brucellosis among animal farmers of Yazd province. Iran J Public Health. 2002; 31 (1-2): 29-32.

21. El Sherbini A, Kabbash I, Schelling E, El Shennawy S, Shalapy N, Elnaby GH, et al. Seroprevalences and local variation of human and livestock brucellosis in two villages in Gharbia Governorate, Egypt. Trans R Soc Trop Med Hyg. 2007; 101 (9): 923-8.

22. Gumi B, Firdessa R, Yamuah L, Sori T, Tolosa T, Aseffa A, et al. Seroprevalence of Brucellosis and Q-Fever in Southeast Ethiopian Pastoral Livestock. JVSMD. 2013; 2 (1): 1-5.
23. Scolamacchia F, Handel IG, Fèvre EM, Morgan KL, Tanya VN, Bronsvoort BMdC. Serological patterns of brucellosis, leptospirosis and Q fever in Bos indicus cattle in Cameroon. PloS one. 2010; 5 (1): 1-11.

24. Mostafavi E, Asmand M. Trend of brucellosis in Iran from 1991 to 2008. Iran J Epid . 2012; 8 (1): 94-101.

25. Dean AS, Crump L, Greter H, Schelling E, Zinsstag J. Global burden of human brucellosis: a systematic review of disease frequency. PLoS Negl Trop Dis. 2012; 6 (10): 1-9.

26. Esmaeili. S, Pourhossein. B, Gouya. MM, Amiri. FB, Mostafavi. E. Seroepidemiological Survey of Q Fever and Brucellosis in Kurdistan Province, Western Iran. Vector Borne Zoonotic Dis. 2014; 14 (1): 41-5.

27. Iranian CDC report. Infection of more than 20 thousand people in the country to brucellosis in last year Ilna. 2016.

28. Pappas G, Papadimitriou P, Akritidis N, Christou L, Tsianos EV. The new global map of human brucellosis. Lancet Infect Dis. 2006; 6 (2): 91-9.

29. Akbarian Z, Ziay G, Schauwers W, Noormal B, Saeed I, Qanee $\mathrm{AH}$, et al. Brucellosis and Coxiella burnetii infection in householders and their animals in secure villages in Herat province, Afghanistan: A cross-sectional study. PLoS Negl Trop Dis. 2015; 9 (10): 1-17.

30. Shabbir MZ, Akram S, ul Hassan Z, Hanif K, Rabbani M, Muhammad J, et al. Evidence of Coxiella burnetii in Punjab province, Pakistan. Acta Trop. 2016; 163: 61-9.

31. Mahmood R, Waheed U, Ali T, Gopaul KK, Dainty AC, Muchowski JK, et al. Serological and Nucleic Acid Based Detection of Brucellosis in Livestock Species and Molecular Characterization of Brucella melitensis Strains Isolated from Pakistan. Int J Agric Biol. 2016; 18 (2): 311-8.

32. Edalati-Shokat H, Abbasi-Doulatshahi E, Hajian-Bidar H, Gharekhani J, Rezaei A-A. Q fever in domestic ruminants: A Seroepidemiological survey in Hamedan, Iran. IJCMAS. 2015; 4 (1): 589-96.

33. Ruiz-Fons F, Astobiza I, Barandika JF, Hurtado A, Atxaerandio R, Juste RA, et al. Seroepidemiological study of Q fever in domestic ruminants in semi-extensive grazing systems. BMC Vet Res. 2010; 6 (3): 1-6.

34. McCaughey C, Murray L, McKenna J, Menzies F, McCullough S, O'neill $\mathrm{H}$, et al. Coxiella burnetii (Q fever) seroprevalence in cattle. Epidemiol Infect. 2010; 138 (01): 21-7.

35. Hong-Bo N, Si-Guo L, Jiang H-F, Chun-Ren W, Ai-Dong Q. Seroprevalence of $\mathrm{Q}$ fever in dairy cows in northeastern China. Afr J Microbiol Res. 2011; 5 (23): 3964-7.

36. Ebrazeh N, Asmar M, Mozafari N. A, Esfandiari B. Investigation of prevalence and incidence brucellosis in Amol of slaughterhouse livestocks. Int J Biol Sci. 2011; 5 (2): 1-9.

37. Mai HM, Irons PC, Kabir J, Thompson PN. A large seroprevalence survey of brucellosis in cattle herds under diverse production systems in northern Nigeria. BMC Vet Res. 2012; 8 (1): 144.

38. Matope G, Bhebhe E, Muma JB, Oloya J, Madekurozwa RL, Lund A, Skjerve E. Seroprevalence of brucellosis and its associated risk factors in cattle from smallholder dairy farms in Zimbabwe. Trop Anim Health Prod. 2011; 43 (5): 975-82.

39. Tijjani A, Musa H, Ousoumanou O, Akintola O. Prevalence of brucellosis in food animals slaughtered at Damaturu abattoir, Yobe State, Nigeria. Sahel J Vet Sci. 2009; 8 (1). 


\section{Ghasemi et al.}

40. Bashiribod H, Rahbarian N, Eslami G, Kazemi B, Jannatsharif E, Mahmoudirad M, et al. Prevalence of coxiella burnetii in human, animal hosts and hard ticks in west mazandaran province Iran, 2003-4. Res in Med. 2008; 32 (3): 253-7.

41. Khalili M, Sakhaee E. An update on a serologic survey of Q fever in domestic animals in Iran. Am J Trop Med Hyg. 2009; 80 (6): 1031-2.

42. Rahimi E, Ameri M, Karim G, Doosti A. Prevalence of Coxiella burnetii in bulk milk samples from dairy bovine, ovine, caprine, and camel herds in Iran as determined by polymerase chain reaction. Foodborne Pathog Dis. 2011; 8 (2): 307-10.

43. Cetinkaya B, Kalender H, Ertas H, Muz A, Arslan N, Ongor $\mathrm{H}$, et al. Seroprevalence of coxiellosis in cattle, sheep and people in the east of Turkey. Aust Vet J. 2000; 56: 181-3.

44. Akbarmehr J, Ghiyamirad M. Serological survey of brucellosis in livestock animals in Sarab City (East Azarbayjan province), Iran. Afr J Microbiol Res. 2011; 5 (10): 1220-3.
45. Maadi $H$, Moharamnejad $M$, Haghi M. Prevalence of brucellosis in cattle in Urmia, Iran. Pak Vet J. 2011; 31 (1): 81-2.

46. Movassagh M. Detection of cows raw milk contamination by Brucella abortus in Ilkhchi region by ELISA method. Iran J Food Tech Nut. 2013; 10 (1): 97-101.

47. Ali S, Ali Q, Abatih EN, Ullah N, Muhammad A, Khan I, et al. Sero-prevalence of Brucella abortus among dairy cattle and buffaloes in Pothohar Plateau, Pakistan. Pak J Zool. 2013; 45 (4): 1041-6.

48. Naeem K KJ, Ullah A. Seroprevalence and risk factors associated with Crimean-Congo haemorrhagic fever and brucellosis in people and livestock in Baluchistan and Khyber Pakhtunkhwa Provinces, Pakistan. South Asia Regional One Health Symposium. 2013. 50-51

49. Akbarian Z ZG, Noormal B, Saeed I, Hussain A, Shahab Z. Survey of the seroprevalence of brucellosis, $Q$ fever and Crimean-Congo haemorrhagic fever in humans and livestock in Herat province, Afghanistan. South Asia Regional One Health Symposium. 2013. 30-33. 